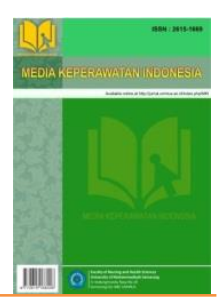

Research article

\title{
Murottal Therapy Lowers Blood Pressure in Hypertensive Patients
}

\author{
Rastia Irmachatshalihah', Yunie Armiyati² \\ 1,2 Program Studi Ilmu Keperawatan, Fakultas Ilmu Keperawatan dan Kesehatan, Universitas Muhammadiyah \\ Semarang
}

\section{Article Info}

Article History:

Accepted September 29th 2019

Key words:

Murrotal therapy;

Hypertension

\begin{abstract}
The incidence of hypertension always increasing every year, the incidence of hypertension increased from $25,8 \%$ to $34.1 \%$ in 2018 . The Hypertension's patients were prone to psychological problems for example stress that could raise the blood pressure. The intervention non-pharmacological for lowering blood pressure is using intervention murottal. This study aims to analyze the influence murottal's therapy to decrease blood pressure in hypertension's patients in the community health center Bandarharjo. The design used was quasy experiment with pre test and post test used purposive samplind and random sampling got result 20 respondents. The results of statistical tests therapy murottal have effected on the blood pressure to hypertension's patient $p$ value $=0,000 \quad(\alpha<0,05)$. Therapy murottal can reduce the blood pressure on then patient hypertension in the work of the comunity health center of bandarharjo. The supposed nurse can do gift treatment murottal intervention can be taught and applied to lower the blood pressure to increase nursing care.
\end{abstract}

\section{PENDAHULUAN}

Hipertensi adalah penyakit tidak menular sebagai kasus tertinggi di Indonesia (Dinkes, 2017). Insiden pada kasus hipertensi selalu mengalami kenaikan setiap tahunnya, prevalensi dari hasil sebuah pengukuran tekanan darah pada kasus hipertensi beranjak mengalami kenaikan dari 25,8\% sampai dengan 34,1\% (Riskesdas, 2018). Penyakit hipertensi bisa menyerang pada semua golongan masyarakat di seluruh dunia (Robert \& Kereh, 2015). Data WHO sebanyak 40\% negara selatan yang mengantongi kasus penderita hipertensi, sedangkan data dari negara maju hanya mengantongi 35\% penderita hipertensi. Daerah Asia Tenggara $36 \%$ kasus dengan usia dewasa pada penderita hipertensi. Terjadi peningkatan kasus darah tinggi dengan jumlah penderita untuk pria maupun wanita di Indonesia dari 18\% sampai dengan 31\% dan 16\% sampai dengan 29\% (Laseduw, 2016). Prevalensi hipertensi di Indonesia tertinggi pada Provinsi Bangka Belitung dengan jumlah penduduk 1.380.762 yaitu sebesar 30,9 \%, sedangkan prevalensi hipertensi terendah pada Provinsi Papua dengan jumlah penduduk 3.486.432 yaitu 16,8\% (Depkes, 2013).

Penderita hipertensi menduduki proporsi terbesar di Indonesia dari semua penyakit

Corresponding author:

Rastia Irmachatshalihah

rastiairma331@gmail.com

Media Keperawatan Indonesia, Vol 2 No 3, Oktober 2019

e-ISSN: 2615-1669

DOI:10.26714/mki.2.3.2019.97-104 
tidak menular yang dilaporkan, pada Provinsi Jawa Tengah yaitu sebesar 64,83\%. Kabupaten atau kota tertinggi yaitu kota Salatiga sebesar $77,72 \%$ sedangkan kota Semarang menempati peringkat ke 31 dengan presentase penyakit hipertensi sebesar 6,88\% (Dinkes, 2017). Insiden kasus hipertensi di Kota Semarang, urutan pertama adalah Puskesmas Bandarharjo dengan jumlah 10,111 kasus sejak bulan Januari sampai September 2018 (Dinkes, 2017). Hasil data UPTD Puskesmas Bandarharjo pada 2 bulan terakhir yaitu Oktober dan November 2018 didapatkan hasil jumlah penderita hipertensi mencapai 1,090 kasus.

Penderita hipertensi rentan terhadap masalah psikologis, diantaranya stres. Suatu individu jika merasa tidak mampu untuk menghadapi segala tekanan-tekanan dalam suatu kehidupan maka individu akan mengalami stress, stres dapat mengakibatkan hipertensi (Fatma, 2018). Stres akan membuat otak melepaskan hormon norepinefrin, adrenalin dan kortisol. Rangsangan pada pusat vasomotor akan menuju bawah dengan suatu metode saraf simpatis hingga ganglia simpatis. Keadaan tersebut dapat menghasilkan penyimpaan ion garam dan air pada tubulus ginjal, sehingga akan terjadi kenaikan kapasitas intra vaskuler serta akan mengakibatkan peningkatan tekanan darah (Smeltzer \& Bare, 2013).

Mejenemen untuk penderita hipertensi secara garis besar dibagi menjadi dua bagian yaitu farmakologi dan terapi komplementer atau non farmakologi. (Priharyanti, Nur Aini, \& Astuti, 2018). Intervensi nonfarmakologi yang dapat di pilih pada pasien hipertensi dengan mendengarkan murottal Al -Quran. Terapi murottal ayat suci Al - Quran bertujuan mengurangi kecemasan dan stres untuk mempercepat proses penyembuhan dengan menurunkan tekanan darah. Ketika seseorang sedang mendengarkan lantunan ayat suci Al - Quran mempunyai dampak relevan untuk mengurangi suatu kekakuan pada saraf otot reflektif (Kaheel, 2013).

Penelitian intervensi nonfarmakologi pasien hipertensi sudah di aplikasikan secara umum namum belum di lakukan penelitian aplikasi murottal pada pasien hipertensi dengan menggunakan surah AlKahfi. Kenaikan tekanan darah pada pasien hipertensi dapat di akibatkan karena stres sehingga intervensi murottal dapat di lakukan untuk menurunkan tekanan darah. Murottal Al-Quran menimbulkan efek meningkatkan relaksasi dan menurunkan tekanan. Penelitian ini bertujuan untuk mengetahui pengaruh terapi murottal terhadap penurunan tekanan darah pada pasien hipertensi.

\section{METODE}

Penelitian ini merupakan penelitian eksperimental dengan desain quasy experiment, rancangan penelitian menggunakan one group pre test and post test tanpa kelompok kontrol. Teknik pengambilan sampel yang di pakai pada penelitian ini yaitu purposive sampling dan random sampling, besar total sampel yang di gunakan pada penelitian ini sebanyak 20 responden dari rumus Federer. Populasi adalah pasien hipertensi perempuan yang mengikuti Prolanis di Puskesmas Bandarharjo sebanyak 80 orang di dapatkan 50 responden sesuai dengan kriteria inklusi yaitu hipertensi primer $\geq 140 / 90 \mathrm{mmHg}$, beragama Islam, menandatangani informed consent, kesadaran composmentis, tidak mengalami gangguan jiwa, tidak mengalami gangguan pendengaran, usia dalam rentan 30 tahun 80 tahun, dan tidak melakukan aktifitas berat 12-24 jam. Random sampling di lakukan untuk mendapatkan 20 responden yang di pilih sebagai subjek penelitian.

Penelitian di lakukan setelah mendapat ethical clearance dari Komisi Etik Penelitian Kesehatan (KPEK) Fakultas Kesehatan Masyarakat Universitas Muhammadiyah Semarang. Peneliti memilih responden yang 
sudah di tentukan sesuai kriteria inklusi kemudian di berikan informed consent pada pasien yang terpilih menjadi responden dalam penelitian, selanjutnya kontrak waktu yang telah di setujui antara peneliti dan responden. Penelitian di awali dengan menjelaskan prosedur penelitian terlebih dahulu.

Instrumen yang digunakan pada penelitian ini adalah instrumen untuk intervensi murottal dan untuk mengukur tekanan darah. Alat untuk mengukur tekanan darah yaitu sphygnomanometer digital yang baru dan sudah terkalibrasi oleh pabrik berstandar nasional Indonesia (SNI). Instrumen untuk mendengarkan murottal yaitu MP3 Player surah Al-Kahfi yag dilantunkan oleh Ali Abdurahman Al Hutaify dan headphone yang menutup seluruh telinga dengan diameter $7 \mathrm{~cm}$.

Intervensi murottal di berikan dengan mengatur posisi responden tidur berbaring rileks dengan mata terpejam. Responden di berikan murottal surah Al-Kahfi yang di lantunkan oleh Ali Abdurahman Al Hutaify menggunakan headphone selama 31 menit 26 detik. Tekanan darah di ukur sebelum dan setelah di berikan intervensi dengan mengunakan sphygmomanometer digital.

Data di analisis secara univariat dan bivariat mengunakan program komputer. Analisis secara univariat dengan menyajikan data numerik dan data kategorik. Data numerik seperti umur, tekanan darah, dan lama menderita hipertensi di sajikan dalam tendensi sentral tendensi sentral (mean, minimal, maksimal dan standar deviasi). Data kategorik seperti pekerjaan dan pendidikan di sajikan dalam distribusi frekuensi (\%). Data di lakukan uji normalitas menggunakan Shapiro Wilk. Uji bivariat pre dan post terapi murottal menggunakan uji paired sample t-test.

\section{HASIL}

Penelitian ini telah dilakukan pada 50 penderita hipertensi. Hasil penelitian yang ditampilkan dalam tabel 1 menunjukan bahwa rata-rata usia responden 50,80 tahun, responden yang memiliki usia tertinggi adalah 80 tahun sedangkan responden yang memiliki usia terendah adalah 37 tahun. Sebagian besar subjek penelitian mengalami hipertensi lebih dari usia 2 tahun. Jenis pekerjaan responden paling banyak ibu rumah tangga sebesar 75\%. Pendidikan akhir responden paling banyak adalah Sekolah Dasar (SD) sebesar $45 \%$, dan paling sedikit pendidikan terakhir perguruan tinggi sebesar $10 \%$.

\section{Tabel 1}

Deskripsi Pasien yang Mengalami Hipertensi Berdasarkan Karakteristik di Wilayah Kerja Puskesmas Bandarharjo, Mei 2019 (n=20)

\begin{tabular}{lllll}
\hline Karakteristik Responden & f & $\%$ & Mean & SD \\
\hline Usia & & & 50,80 & 10,97 \\
Lama menderita hipertensi & & & 2,90 & 2,82 \\
Pekerjaan : & & & & \\
1. Ibu rumah tangga & 15 & 75 & & \\
2. Swasta & 5 & 25 & & \\
Tingkat pendidikan : & & & \\
1. SD & 9 & 45 & \\
2. SMP & 4 & 20 & \\
3. SMA & 5 & 25 & \\
4. Sarjana & 2 & 10 & \\
\hline
\end{tabular}

Hasil penelitian yang disajikan dalam tabel 2 menunjukan bahwa tekanan darah sistolik sebelum dilakukan intervensi murottal di dapatkan rata - rata 153,50 mmHg, sesudah intervensi rata - rata 129,50 mmHg. Terdapat selisih penurunan tekanan darah sistolik sebelum dan setelah di lakukan intervensi murottal sebesar 24 mmHg. Tekanan darah diastolik sebelum di berikan intervensi murottal di dapatkan rata-rata $106,95 \mathrm{mmHg}$, setelah di berikan intervensi murottal di dapatkan rata - rata 83,80 mmHg. Terdapat selisih penurunan tekanan darah diastolik sebelum dan setelah dilakukan intervensi murottal sebesar 23,15 mmHg. MAP sebelum dilakukan intervensi murottal 122,46 setelah dilakukan terapi murottal 99,03. Terdapat selisih MAP sebelum dan sesudah 
di lakukan intervensi murottal sebesar $23,43 \mathrm{mmHg}$.

Tabel 2

Deskripsi Tekanan Darah Sebelum dan Sesudah Dilakukan Intervensi Murottal di Wilayah Kerja Puskesmas Bandarharjo, Mei 2019 (n=20)

\begin{tabular}{lcc}
\hline Tekanan darah (mmHg) & Mean & $\begin{array}{c}\text { Standar Deviasi } \\
\text { (SD) }\end{array}$ \\
\hline Sebelum & & \\
Sistolik & 153,50 & 9,74 \\
Diastoik & 106,95 & 11,82 \\
Mean Arterial Pressure & 122,46 & 9,85 \\
Sesudah & & \\
Sistolik & 129,50 & 12,34 \\
Diastoik & 83,80 & 9,37 \\
Mean Arterial Pressure & 99,03 & 8,17 \\
\hline
\end{tabular}

Berdasarkan tabel 3 hasil penelitian menunjukan sistolik, diastolik dan MAP data berdistribusi normal $(p>0,05)$. Uji bivariate di pilih menggunakan uji paired $t$ test, dijelaskan pada tabel 4.

Tabel 3

Uji Normalitas Data Tekanan Darah Sebelum dan Sesudah Dilakukan Intervensi Murottal di Wilayah Kerja Puskesmas Bandarharjo, Mei 2019 (n=20)

\begin{tabular}{lcc}
\multicolumn{1}{c}{ Variabel } & $p$ value & Kesimpulan \\
\hline Sistolik & & \\
Sebelum & 0,796 & Normal \\
Sesudah & 0,496 & Normal \\
Diastolik & & \\
Sebelum & 0,127 & Normal \\
Sesudah & 0,193 & Normal \\
Mean Arterial & & \\
Pressure & & \\
Sebelum & 0,553 & Normal \\
Sesudah & 0,401 & Normal \\
\hline
\end{tabular}

*Shappiro Wilk

Hasil penelitian yang disampaikan dalam tabel 4 menunjukan perbedaan signifikan selisih rata-rata tekanan darah sebelum dan setelah pemberian intervensi murotal. Ada pengaruh intervensi murottal terhadap penurunan tekanan darah pada pasien hipertensi di wilayah kerja Puskesmas Bandarharjo Semarang ( $p$ value $=0,000$ $<0,05$ ).
Tabel 4

Uji Beda Tekanan Darah Sebelum dan Sesudah Diberikan Intervensi Murottal di Wilayah Kerja Puskesmas Bandarharjo, Mei $2019(\mathrm{n}=20)$

\begin{tabular}{lccc}
\multicolumn{1}{c}{ Variabel } & Mean & $\mathrm{t}$ & $p^{*}$ \\
\hline Sistolik & & & \\
Sebelum - sesudah & 24,00 & 8,455 & 0,000 \\
Diastolik & & & \\
Sebelum - sesudah & 23,15 & 9,727 & 0,000 \\
Sebelum - sesudah & 23,43 & 10,91 & 0,000 \\
\hline *Uji paired t-test & & &
\end{tabular}

\section{PEMBAHASAN}

Penelitian menunjukan hasil bahwa ratarata usia responden 50,80 tahun. Responden yang memiliki usia tertinggi adalah 80 tahun sedangkan responden yang memiliki usia terendah adalah 37 tahun. Tingginya penyakit hipertensi dipengaruhi dengan sejalannya usia bertambah di karenakan adanya perubahan struktur dari pembuluh darah besar, sehingga pembuluh darah akan terjadi penyempitan dinding pembuluh darah akan menjadi kaku (Raharjeng \& Tuminah, 2015).

Berdasarkan penelitian terdahulu sebagaian besar subjek menderita hipertensi berusia 60 tahun (Prasetyo, 2015). Pernyataan ini selaras dengan kejadian hipertensi akan berbanding lurus dengan bertambahnya usia, karena arteri akan berkurang elastisitas dan kelenturannya sehingga sistolik akan meningkat seiring dengan bertambahnya usia (Potter \& Perry, 2010). Manfaat murottal terhadap usia lanjut / lansia dapat mengakibatkan ketentraman dan kenyamaan sehingga pada lansia efektif di lakukan terapi murottal (Agus, 2009).

Sebagian besar subjek penelitian mengalami hipertensi lebih dari usia 2 tahun. Lama menderita hipertensi akan mempengaruhi peningkatan tekanan darah. Semakin lama pasien menderita hipertensi akan memicu kerusakan jantung, seperti pembesaran vertikel, abnormalitas aliran arteri koroner dan disfungsi sistolik diastolic (Wahyuningsih \& Amalia, 2018). Semakin lama pasien menderita hipertensi akan memunculkan penyakit lanjutan 
seperti infrak miokard yang disebabkan karena arteri koroner terjadi aterosklerotik tidak mampu mensuplai oksigen ke miokardium maupun terbentuknya trombus sehingga akan menutup aliran darah oksigen pada miokardium kemudian akan menyebakan iskemia jantung sehingga terjadi infrak (Corwin, 2009). Stroke juga dapat terjadi akibat hipertensi karena danya perdarahan tekanan tinggi pada otak maupun adanya embolus yang terlepas dari pembuluh darah non otak yang terpanjang tekanan tinggi, sehingga arteri otak akan mengakibatkan aterosklerosis dapat menjadi lemak menjadi terbentuknya aneurisma (Ardiansyah, 2012).

Penelitian ini menunjukan bahwa jenis pekerjaan tertinggi yaitu sebagai ibu rumah tangga dengan presentase $75 \%$ dan sebanyak 15 responden. Pekerjaan sebagai ibu rumah tangga cenderung memiliki aktifitas yang ringan, berbeda dengan wanita yang berkerja yang cenderung di luar rumah memiliki aktifitas yang lebih dibandingkan dengan aktifitas sebagai ibu rumah tangga. Aktifitas yang tinggi dapat mencegah hipertensi sehingga bisa menurunkan tekanan darah pada pasien hipertensi (Gibney, 2016).

Penelitian ini selaras dengan penelitian lain yang mengungkapkan bahwa banyak dari ibu rumah tangga hanya berdiam diri di rumah sehingga menyebabkan perasaan bosan. Berbeda dengan ibu yang bekerja mereka memiliki kegiatan lain, meskipun mereka cenderung mempunyai kegiatan yang banyak maka mereka akan meluangkan waktu hanya sekedar berolahraga, biasanya ibu yang berkerja lebih aktif di bandingkan dengan ibu rumah tangga (Laras \& Yessi, 2016). Orang yang tidak aktif olahraga akan menyebabkan kegemukan, olahraga dapat mengantisipasi kelebihan berat badan serta menurunkan pemasukan garam ke dalam tubuh, sehingga garam keluar melalui peluh, olahraga juga menurunkan tahanan perifer sehingga dapat mencegah hipertensi (Prasetyo, 2015).

Penelitian ini menunjukan sebagian besar berpendidikan Sekolah Dasar (SD) berjumlah 9 responden dengan presentase $45 \%$, dan minoritas dengan pendidikan terakhir yaitu perguruan tinggi berjumlah 2 responden dengan presentase $10 \%$, tingkat pendidikan akan mempengaruhi pengetahuan tentang hipertensi. Pendidikan mempunyai suatu peranan terpenting untuk menentukan kualitas hidup manusia. Melalui pendidikan, pengetahuan dan informasi tentang cara perawatan hipertensi. Semakin tinggi tingkat pendidikan berdampak pada semakin tinggi kualitas hidup manusia untuk menangani hipertensi (Chandra, 2015).

Penelitian ini selaras dengan penelitian lain yang mengemukakan tingkat pendidikan akan mempengaruhi kemampuaan seseorang dan wawasan seseorang dalam penerapan life style yang sehat, dalam mencegah penyakit hipertensi. Semakin tinggi tingkat pendidikan maka semakin tinggi usaha seseorang dalam menjaga gaya hidup agar tetap sehat (Laras \& Yessi, 2016). Tingginya resiko hipertensi pada pendidikan yang rendah karena minimnya pengetahuan pada seseorang terhadap kesehatan dan lambat menerima informasi yang di berikan oleh petugas kesehatan sehingga berdampak pada pola hidup sehat (Anggara \& Prayitno, 2013).

Hasil penelitian menunjukan nilai rata-rata tekanan darah sistolik maupun diastolik sebelum dilakukan intervensi murottal 153,50 mmHg dan 106,95 mmHg. Tekanan darah sistolik dan diastolik sesudah intervensi murottal rata-rata $129,50 \mathrm{mmHg}$ dan 83,80 mmHg. Selisih penurunan tekanan darah sistolik dan diastolik sebelum dan setelah intervensi murottal yaitu $24 \mathrm{mmHg}$ dan 23,15 mmHg. Penelitian ini membuktikan bahwa ada perbedaan tekanan darah sebelum dan setelah diberikan intervensi murottal pada pasien 
hipertensi di wilayah kerja Puskesmas Bandarharjo Semarang ( $p$ value $<0,005$ ).

Penelitian terhadap pasien hipertensi di ruang cempaka RSUD dr. H. Soewondo Kendal juga menunjukan ada pengaruh terapi murottal Al- Quran surah Ar Rahman (Aini \& Wulandari, 2018). Teknik murottal dapat meningkatkan efek rilaksasi sehingga akan lebih efisien sebagai penurun tekanan darah. Mekanisme murottal sebagai penurun tekanan darah saat pemberian murottal gelombang suara akan masuk melalui telinga pinna kemudian di belokan saluran telinga luar sehingga gelombang suara akan menggetarkan gelombang thympani getaran tersebut akan mengakibatkan tulang ditengah telinga seperti maleus - incus - staper bergetar kemudian hipotalamus akan mempengaruhi struktur basal forebrain yang termasuk sistem saraf limbik, hipotalamus adalah saraf pusat otonom yang mengatur sistem pernafasan, denyut jantung, tekanan darah, fungsi endokrin dan memori (Rilla, Ropi, \& Sriati, 2014).

Penelitian menunjukan perbedaan signifikan selisih rata-rata tekanan darah sebelum dan setelah pemberian intervensi murotal. Ada pengaruh intervensi murottal terhadap penurunan tekanan darah pada pasien hipertensi di wilayah kerja Puskesmas Bandarharjo Semarang ( $p$ value $=0,000<0,05)$. Hasil penelitian memperkuat penelitian yang ada sebelumnya tentang efektifitas murottal surat Al-Kahfi. Penelitian sebelumnya dengan murottal surah Ar-Rahman menurunkan tekanan darah pada pasien hipertensi di Puskesmas Kedungmundu menunjukan penurunan tekanan darah sistolik 9,93\%, tekanan darah diastolik 8,96\%, MAP 9,9\%, sedangkan penurunan tekanan darah pada kelompok kontrol, tekanan darah sistol 1,84\%, tekanan darah diastolik 0,96\%, dan MAP 1,22\% (Auliyak, 2014). Penelitian ini menunjukan penurunan tekanan darah sistolik 15,63\%, diastolik 21,64\%, MAP 19,13\%. Hasil penelitian pemberian murottal surah Al-
Kahfi selama 31 menit 26 detik lebih efektif untuk menurunkan tekanan darah dari penelitian sebelumnya.

Pemberian terapi murottal surah Al-Kahfi efektif terhadap penurunan tekanan darah. Penurunan tekanan darah terjadi karena respon relaksasi. Terapi murottal dapat memicu sistem saraf parasimpatis sebagai pengaruh yang berlawanan dengan saraf simpatis. Terjadi keseimbangan antara dua saraf autonom tersebut, maka akan menjadikan prinsip dasar sebagai timbulnya respon relaksasi, Rangsangan auditori murottal mempunyai efek relaksasi yang meningkatkan endorphin dalam kontrol desenden dan membuat relaksasi otot (Sokeh, Armiyati, \& Chanif, 2013). Respon tersebut merupakan terjadinya keseimbangan antara sistem saraf simpatis dan parasimpatis (Octora \& Purnawan, 2016).

Manfaat dari terapi Al-Quran untuk menurunkan stres, kesedihan, dan dapat memperoleh ketenangan jiwa sehingga memberikan pengaruh besar bagi kehidupan jasmani maupun rohani (Fadilah, 2016). Murottal Al-Quran mampu menurunkan tingkat stres sehingga dapat menurunkan tekanan darah (Rahayu, Hidayati, \& Imam, 2018). Terapi murottal Al-Quran adalah suatu terapi religi yang akan memberi efek terapeutik bagi orang yang mendengarkannya. Rangsangan yang diberikan pada auditori murottal memiliki dampak dari distraksi yaitu peningkatan pembentukan hormon endorphin pada sistem kontrol desenden. Kenaikan pada total hormon endorphin akan mengakibatkan otot relaksasi maupun sebagai pengubahan perhatian dari rasa sakit. Terapi murottal akan menstimulasi hipotalamus yang berguna untuk memproduksi neuropeptida, neuropeptida nantinya akan mempunyai dampak bagi tubuh yaitu kenyamanan diperoleh melalui penurunan jumlah hormon kortisol, epineprin, norepinefrin, dan dopamin (Siswoyo, 2017). 
Surat Al - Kahfi yang di dengarkan dalam penelitian ini memiliki tempo $101 \mathrm{bpm}$, harmony reguler dan consistent, ryhm andate (mendayu - dayu), volume 60 decibel, intensitas medium aplitudo, yang memiliki dampak dari relaksasi. Mendengarkan murottal surah Al-Kahfi termasuk dalam intervensi Religious Ritual Enchancement merupakan suatu teknik relaksasi menghilangkan stress, yang didalamnya mengandung unsur - unsur religi dan spiritual (Bluecheck \& Docthermen, 2015). Kondisi rileks akan mengantisipasi vasospasme pembuluh darah yang disebabkan perangsangan saraf simpatis karena pada kondisi stres perfusi darah akan meningkat (Laitupa \& Amin, 2016).

Berdasarkan pada hasil penelitian terapi murottal surah Al-Kahfi efektif menurunkan tekanan darah karena memberikan ketenangan kepada responden yang mendengarkan di lingkungan yang tenang dan tanpa suara yang dapat menggangu responden. Respon positif murottal surah Al-Kahfi mempengaruhi hipotalamus mengeluarkan hormon endoprin membuat relaksasi dan meurunkan tekanan darah pada pasien hipertensi. Terapi murottal ini juga merupakan terapi tanpa efek samping yang aman dan mudah sehingga dapat di lakukan secara rutin oleh penderita hipertensi sebagai terapi mandiri di rumah.

\section{SIMPULAN}

Simpulan penelitian ini terdapat penurunan tekanan darah sistolik, diastolik dan MAP sebelum dan sesudah di berikan intervensi murottal. Ada pengaruh terapi murottal terhadap penurunan tekanan darah pada pasien hipertensi di buktikan dengan $p$ value $0,000(\mathrm{p}<0,05)$.

\section{UCAPAN TERIMAKASIH}

Penulis ingin mengucapkan terima kasih kepada semua responden dalam penelitian ini.

\section{REFERENSI}

Agus. (2009). Terapi murottal terhadap tekanan darah pada lansia. Jurnal Untan, 2(1), 8.

Anggara, \& Prayitno. (2013). Faktor-faktor yang berhubungan dengan tekanan darah di Puskesmas Telaga Murni. Jurnal Ilmiah Kesehatan, 5(1), 20-25.

Ardiansyah. (2012). Medikal bedah untuk mahasiswa. Yogyakarta: DIVA Press.

Auliyak. (2014). Pengaruh terapi murottal terhadap penurunan tekanan darah pada pasien hipertensi. Jurnal Online Mahasiswa, 3(4), 15.

Bluecheck, \& Docthermen. (2015). Nursing intervention classification. Lowa: Mosliever.

Corwin, E. (2009). Buku saku patofisiologi edisi 3. Jakarta: EGC.

Depkes. (2013). Profil kesehatan Indonesia. Retrieved October 10, 2018, from http://www.depkes.go.id/resources/downloa d/profil/PROFIL_KAB_KOTA_2013/3374_Jate ng_Kota_Semarang_2013.pdf

Dinkes. (2017). Profil kesehatan kota semarang 2017. Retrieved November 12, 2018, from http://dinkes.semarangkota.go.id/asset/uplo ad/Profil/Profil/Profil Kesehatan 2017.pdf

Fatma, H. (2018). Relaksasi untuk mengurangi stres pada penderita hipertensi esensial. Humanitas, 12(1), 12-28.

Gibney. (2016). Gizi kesehatan masyarakat. Jakarta: EGC.

Kaheel, A. (2013). Sembuhkan sakitmu dengan AlQuran. Yogyakarta: Laras Media Prima.

Laitupa, A. A., \& Amin, M. (2016). Ventilasi dan perfusi, serta antara ventilasi dan perfusi. Jurnal Respirasi, 2(1), 7.

Laras, P., \& Yessi, H. (2016). Pengaruh teknik relaksasi benson dan murottal Al-Quran terhadap tekanan darah penderita hipertensi primer. Jurnal Online Mahasiswa, 10(2), 122.

Laseduw. (2016). Hipertensi di Indonesia.

Octora, S. D., \& Purnawan, I. (2016). Pengaruh terapi murottal terhadap kualitas tidur lansia. Jurnal Keperawatan Sudirman, 11(3), 24. 
Potter, P., \& Perry, A. (2010). Fundamental keperawtan: konsep, proses, dan praktik volume 1 edisi 7. Jakarta: Salemba Medika.

Prasetyo, D. A. (2015). Faktor-faktor yang berhubungan dengan hipertensi pada usia dewasa muda. Jurnal Online Mahasiswa Universitas Muhammadiyah Semarang, 8(2), 107-111.

Priharyanti, W., Nur Aini, D., \& Astuti, S. P. (2018). Pengaruh terapi murottal terhadap tekanan darah pada pasien hipertensi di ruang cempaka RSUD dr.H. Soewondo. Jurnal Keperawatan, $3(2), 2$.

Raharjeng, \& Tuminah. (2015). Prevalensi hipertensi dan determainnya di Indonesia. Jakarta: Majalah Kedokteran Indonesia.

Rahayu, D. A., Hidayati, T. N., \& Imam, T. A. (2018). The Effect Of Murottal Therapy In Decreasing Depression of Patients Undergoing Hemodialysis, 1(18), 9. https://doi.org/10.26714/mki.1.2.2018.6-10

Rilla, E. V., Ropi, H., \& Sriati, A. (2014). Terapi murottal efektif menurunkan tingkat nyeri dibanding terapi musik pada pasien pasca bedah. Jurnal Keperawatan Indonesia, 17(2), 60-61.

Robert, \& Kereh. (2015). Gambaran faktor yang berhubungan dengan kejadian hipertensi pada guru di SD Gimim IV Tomohon. Keperawatan Indonesia, 3(1), 355.

Smeltzer, S. C., \& Bare, B. G. (2013). Buku ajar keperawatan medikal bedah. Jakarta: EGC.

Sokeh, Armiyati, Y., \& Chanif. (2013). Pengaruh perangsangan auditori murrotal ( ayat-ayat suci Al-Quran ) terhadap nyeri pada pasien yang terpasang ventilator mekanik di ruang ICU Rumah Sakit Islam Sultan Agung Semarang. Retrieved July 12, 2019, from https://jurnal.unimus.ac.id/index.php/psn12 012010/article/view/864/918

Wahyuningsih, S., \& Amalia, M. (2018). Pengaruh derajat hipertensi, lama hipertensi, dan hiperlipidemia dengan gagal jantung dan gagal ginjal pasien hipertensi. Jurnal Kesehatan Masyarakat Indonesia, 10(1), 22. 